Байкальский государственный университет, г. Иркутск, Российская Федераиия,

Н. Н. Таскаев

Байкальский государственный университет, г. Иркутск, Российская Федерация

\title{
ПРОБЛЕМЫ АДМИНИСТРАТИВНО-ПРАВОВОГО РЕГУЛИРОВАНИЯ ФУНКЦИОНИРОВАНИЯ ВОДНОГО ТРАНСПОРТА В РОССИИ
}

\begin{abstract}
АНнотАЦия. В настоящее время органы государственной власти стремятся реагировать на любую проблему в обществе путем государственного регулирования соответствующей сферы общественной жизни. Само существование возникающей проблемы представляется результатом недостаточного государственного регулирования. В статье на примере законодательства, регулирующего деятельность водного транспорта, подвергнута анализу эффективность государственного регулирования на стадии правовой регламентации. При оценке целесообразности государственного регулирования и осуществления государственного контроля (надзора) выносится предположение, что государственные надзорные органы заинтересованы в некачественном проведении проверки, так как в противном случае деятельность надзорных органов резко сократит экономическую деятельность в поднадзорной сфере, что в конечном счете приведет к сокращению самих надзорных государственных органов. По результатам проведенного анализа делается вывод о необходимости снижения уровня государственного регулирования водного транспорта, которое должно выразиться в сокращении обязательных требований к субъектам экономической деятельности.
\end{abstract}

кЛЮЧЕВЫЕ СЛОВА. Морской и речной транспорт; государственное управление; правовое регулирование; аварии на водном транспорте.

ИНФОРМАЦИЯ О СТАТЬЕ. Дата поступления 2 августа 2016 г.; дата принятия к печати 5 сентября 2016 г.; дата онлайн-размещения 30 сентября 2016 г.

\author{
A. N. Ustinov \\ Baikal State University, \\ Irkutsk, Russian Federation, \\ N. N. Taskayev \\ Baikal State University, \\ Irkutsk, Russian Federation
}

\section{PROBLEMS OF ADMINISTRATIVE AND LEGAL REGULATION OF FUNCTIONING OF WATER TRANSPORT IN RUSSIA}

\begin{abstract}
Today the governmental bodies aim at responding any problem in the society through governmental regulation of the respective sphere of public life. The very existence of the arising problem seems to be a result of insufficient governmental regulation. The article, using the example of legislation regulating activities of the water transport, analyzes the efficiency of governmental regulation at the stage of legal rulemaking. In assessing feasibility of governmental regulation and implementation of the governmental control (supervision), there arises an assumption that the governmental supervisory authorities are interested in low-quality conducting of checks, otherwise, the activities of supervisory authorities will sharply reduce the economic activity in the regulated sphere, which eventually will lead to reducing the supervising governmental bodies as they are. Based on the results, the article draws a conclusion on the necessity of decreasing the level of governmental regulation of the water transport,
\end{abstract}

(C) А. Н. Устинов, Н. Н. Таскаев, 2016

\section{Baikal Research Journal}


which must manifest itself in cutting down the obligatory requirements to the subjects of economic activity.

KEYWORDS. Sea and river transport; governmental management; legal regulation; water transport accidents.

ARTICLE INFO. Received August 2, 2016; accepted September 5, 2016; available online September 30, 2016.

Водный транспорт, прежде всего, морской и речной, является наиболее универсальным транспортом, имеющим наименьшие ограничения по массо-габаритным характеристикам перевозимых грузов и количеству перевозимых пассажиров. Морской и речной виды транспорта в ряде случаев являются единственными транспортными артериями, связывающими некоторые районы и местности Российской Федерации с остальной страной.

Значение водного транспорта для страны и ее экономического развития невозможно переоценить. По состоянию на 2016 г. на долю внутреннего водного транспорта в Российской Федерации приходится менее 1,5 \% общего объема перевозок грузов и грузооборота всех видов транспорта ${ }^{1}$. Таким образом, по грузообороту российский водный транспорт уступает только железнодорожному и трубопроводному, а по пассажирообороту - железнодорожному и автомобильному с учетом того, что железными дорогами охвачена только половина страны, а автомобильный транспорт располагает абсолютно неудовлетворительной сетью дорог. Таким образом, можно говорить о катастрофически низкой транспортной обеспеченности Российской Федерации, что отражает весьма неустойчивое положение российской экономики.

Поскольку площадь Российской Федерации составляет более 17 млн км ${ }^{2}$, транспорт представляет собой ту сферу деятельности, которая влияет на все сферы общественной жизни. Водный транспорт, как и любой другой вид транспорта, представляет повышенную опасность. По указанным причинам российское государство стремится регулировать указанную сферу деятельности, традиционно доводя контроль до гипертрофированного уровня, начало чему было положено еще в 20 -е гг. XX в. [1, с. 58; 2, с. 125], что не может самым отрицательным образом сказаться на экономической деятельности. Несмотря на важность государственного контроля (надзора) в механизме государственного регулирования $[3$, c. $51 ; 4$, с. 9], нельзя не отметить, что существующие его принципы требуют корректировки.

Нашумевшее крушение пассажирского теплохода «Булгария» 10 июля 2011 г. является наглядным тому примером [5, с. 31]. Несмотря на наличие государственного контроля (надзора) за водным транспортом, теплоход имел отверстия в борту, неисправности ряда механизмов, что нарушало транспортную безопасность судна [6, с. 44]. Государственное регулирование деятельности водного транспорта не обеспечило комплектование команды пассажирского теплохода квалифицированным экипажем - в результате корабль вышел в рейс в штормовую погоду без разрешения диспетчера с открытыми бортовыми иллюминаторами [7]. Данная катастрофа наглядно иллюстрирует, что даже регламентированная самым подробным образом деятельность контролирующих органов, экипажа, а также технического состояния судна не в состоянии обеспечить безопасность водного транспорта.

${ }^{1}$ О Стратегии развития внутреннего водного транспорта Российской Федерации на период до 2030 года : распоряжение Правительства РФ от 29 февр. 2016 г. № 327-р // Российская газета. 2016. 3 марта.

\section{Baikal Research Journal}


Представляется, что во многом проблема водного транспорта является общей для всей Российской Федерации - попытка подменить общественные отношения деятельностью государственных органов. Российское государство на протяжении многих веков упорно отрицает возможность саморегулирования общественных отношений без участия государства, так как исходит из предположения, что не урегулированные государством общественные отношения «представляют из себя хаос», и в случае отсутствия государственного регулирования неминуемо наступление общественно опасных последствий, что приводит, в итоге, к нарушению прав человека [8, с. 2] и нарушает безопасность предпринимательской деятельности $[9$, с. $26 ; 10$, с. $53 ; 11$, с. 109$]$.

Катастрофа «Булгарии» и многочисленные менее известные аварии и катастрофы указывают на то, что это утверждение не соответствует действительности. Формально «Булгария» имела все необходимые документы для эксплуатации, выданные государственными органами, которые привычно «закрыли глаза» на отверстия в борту, и то, что ряд судовых механизмов не работоспособен. Как утверждают работники водного транспорта, зачастую сотрудники контролирующих водный транспорт государственных органов, выдавая документы о готовности судна к эксплуатации, не поднимаются на борт судна. Таким образом, говорить о государственном контроле (надзоре), как о гарантии от наступления общественно опасных последствий, не приходится.

Представители контролирующих водный транспорт государственных органов, а также непосредственно работники водного транспорта утверждают, что в случае осуществления государственного контроля (надзора) в полном объеме значительная часть судов просто не будет допущена до эксплуатации, таким образом, будет нанесен существенный вред экономической деятельности. Самым парадоксальным образом то, что ведение государственного контроля (надзора) за водным транспортом в полном объеме не является целесообразным для контролирующих органов. Снижение количества водного транспорта приведет к сокращению численности контролирующих органов по причине уменьшения объемов работы, в связи с чем каждый сотрудник контролирующих органов понимает, что проведение проверки в полном объеме и массовый недопуск судов к эксплуатации со временем неминуемо приведет к массовым сокращениям в его ведомстве, и возможно именно он в результате лишится работы. Исходя из этого, должностные лица государственных органов заинтересованы проводить проверки в неполном объеме, не допуская сокращения объемов своей работы, тем более что за проведение проверки в неполном объеме, как правило, следует «благодарность», увеличивающая уровень коррупции в надзирающих за водным транспортом государственных органах.

В свете абсолютно неудовлетворительного состояния транспорта в России необходимо сформулировать задачи по совершенствованию законодательства и правоприменения в рассматриваемой сфере.

Главной задачей российского законодательства, регламентирующего деятельность водного транспорта и строительство сопутствующей инфраструктуры, как представляется, является устранение монополии государственных субъектов хозяйственной деятельности в сфере транспорта, сокращение издержек транспортных операторов, повышение роли негативной гражданско-правовой ответственности транспортных операторов, сопровождаемое исключением уголовной, административной ответственности, а также снижением административной нагрузки на бизнес, задействованный в сфере транспорта. Кроме того, необходимо «создание равных и экономически выгодных условий коммерческой деятельности на внутреннем водном транспорте» [12, с. 2].

\section{Baikal Research Journal}


Важнейшими нормативными актами, регламентирующими транспортные, в том числе водные, правоотношения в России, являются Водный кодекс РФ, Кодекс внутреннего водного транспорта РФ (КВВТ РФ), а также Кодекс торгового мореплавания РФ.

Деятельность водного транспорта также регулируются Федеральным законом «О лицензировании отдельных видов деятельности» от 4 мая 2011 г. № 99-ФЗ, который устанавливает, что лицензированию подлежит деятельность по перевозкам пассажиров внутренним водным и морским транспортом, а также опасных грузов внутренним водным и морским транспортом. В соответствии с указанным законом было принято Постановление Правительства РФ «О лицензировании отдельных видов деятельности на морском и внутреннем водном транспорте» от 6 марта 2012 г. № 193. Обозначенное постановление Правительства РФ устанавливает, что для получения лицензии на перевозку пассажиров внутренним водным транспортом требуется наличие восьми различных свидетельств. Представляется, что подобное количество лицензий является избыточным. Например, свидетельство о годности судна к плаванию; судовое санитарное свидетельство; свидетельство о предотвращении загрязнения окружающей среды с судна; свидетельство или сертификат о минимальном составе экипажа судна; свидетельство о классификации; мерительное свидетельство, можно было бы заменить единым свидетельством о готовности судна к плаванию. Однако, как представляется, государственные органы, выдающие указанные свидетельства, заинтересованы в том, чтобы осуществлять надзор в этой сфере, обеспечивая себя работой. Передача всех полномочий в один орган противоречит ведомственным интересам государственных органов.

Многие требования Положения о лицензировании деятельности по перевозкам внутренним водным транспортом, морским транспортом пассажиров являются декларативными и либо дублируются другими документами, либо на практике не применяются. Например, судовое свидетельство об управлении безопасностью, предусмотренное ст. 34.1 КВВТ РФ, подтверждает то, что судовладелец принял совокупность документированных мер, необходимых для эффективного выполнения судами требований в области обеспечения безопасности судоходства и предотвращения загрязнения окружающей среды, действий работников судовладельцев, включая членов экипажей судов, в случае возникновения связанных с судами опасности, аварийных ситуаций. Таким образом, судовое свидетельство является классическим документом о документе и вполне может быть отменено с установлением дополнительных требований для получения свидетельства о готовности судна к плаванию.

Для получения указанного свидетельства необходимо наличие 14 требований, например, инструкции работникам судовладельца по обеспечению безопасной эксплуатации судов и предотвращению загрязнения окружающей среды в соответствии с требованиями КВВТ РФ; документ, устанавливающий полномочия и взаимодействие членов экипажей в части обеспечения безопасной эксплуатации судов и предотвращения загрязнения окружающей среды; программы учений экипажа судна по действиям в условиях аварийной ситуации и т. д. Вместе с тем, большая часть указанных требований по смысловой нагрузке дублирует друг друга и вполне может быть сформулирована как инструкции работникам судовладельца по обеспечению безопасной эксплуатации судов и предотвращению загрязнения окружающей среды в соответствии с требованиями ККВТ РФ.

В свою очередь, помимо указанных 14 условий, необходимых для получения судового свидетельства об управлении безопасностью, имеются требования, установленные Приказом Минтранса России «Об утверждении Правил разработки и применения системы управления безопасностью судов» от 11 сентября 2013 г.

\section{Baikal Research Journal}

электронный научный журнал Байкальского государственного университета 
№ 287 (далее - Приказ Минтраса России № 287). Кроме того, представляет определенный интерес необходимость получения судового свидетельства об управлении безопасностью, которое устанавливается одним нормативным актом, требования его получения регламентируются вторым нормативным актом, а порядок выполнения требований - третьим нормативным актом, что нельзя считать удачным нормативным регулированием.

Приказ Минтраса России № 287 (п. 5-7) устанавливает:

«5. В соответствии с пунктом 4 статьи 34.1 КВВТ РФ судовладелец должен обеспечить:

1) соответствие капитана судна профессиональным и квалификационным требованиям в зависимости от района эксплуатации судна и его типа;

2) ознакомление капитана судна с системой управления безопасностью (далее - СУБ);

3) безопасное выполнение капитаном судна своих обязанностей.

6. В число мер по обеспечению надежности механизмов, устройств, оборудования судов, в том числе регулярных проверок механизмов, устройств, оборудования, которые не используются постоянно, должны входить:

1) определение и документирование судовладельцем видов, периодичности, объемов и содержания технического обслуживания и ремонта судна, его механизмов, устройств и оборудования;

2) проведение проверок технического состояния судна, его механизмов, устройств и оборудования через установленные обязательными требованиями и документами изготовителя интервалы времени;

3) определение механизмов, устройств и оборудования судна, внезапный отказ которых может привести к возникновению транспортных происшествий, опасных и аварийных ситуаций, предусмотреть меры, обеспечивающие надежность работы таких механизмов, устройств и оборудования.

7. Учения экипажа судна по действиям в условиях аварийной ситуации в соответствии с программами, указанными в подпункте 9 пункта 3 настоящих Правил, должны проходить в сроки, установленные судовладельцем, если иное не предусмотрено законодательством Российской Федерации. Судовладельцем должен быть установлен порядок документирования информации об указанных учениях» .

Таким образом, данный приказ вместо 14 требований для получения судового свидетельства об управлении безопасностью, установленных ККВТ РФ, фактически вводит только 7.

Важно учитывать, что на международном уровне при разработке нормативно-распорядительной документации по вопросам безопасности плавания судов и организации практической работы по обеспечению безопасной эксплуатации судов применяется Международный кодекс по управлению безопасной эксплуатацией судов и предотвращением загрязнения (далее - МКУБ), принятый 18 сессией Международной морской организации.

МКУБ установил, что «каждая компания должна разработать, задействовать и поддерживать СУБ, которая включает следующие функциональные требования:

- политику в области безопасности и защиты окружающей среды;

- инструкции и процедуры для обеспечения безопасной эксплуатации судов и защиты окружающей среды согласно соответствующему международному праву и законодательству государства флага;

- установленный объем полномочий и линия связи между персоналом на берегу и на судне, а также внутренней связи;

- порядок передачи сообщений об авариях и случаях несоблюдения положений настоящего Кодекса;

\section{Baikal Research Journal}


- порядок подготовки к аварийным ситуациям и действий по их устранению;

- порядок проведения внутренних проверок и обзора управления».

Таким образом, на международном уровне установлено 6 требований к внутренним распорядительным документам судовладельца.

Таким образом, применительно к внутренней документации по охране окружающей среды компании судовладельца в КВВТ РФ установлено 14 требований, Приказом Минтраса России № 287 - только 7, а МКУБ - 6. Бо́льшее количество требований к внутренним документам, регламентирующим охрану окружающей среды и закрепленным в КВВТ РФ, вовсе не свидетельствует о лучшем качестве правовой регламентации, так как многие пункты фактически дублируют друг друга. Обилие требований при дублировании формулировок позволяет государственным надзорным органам требовать наличия новых и новых внутренних документов в компании судовладельце, что в конченом счете является коррупциогенным фактором - надзорный орган фактически может менять объем требуемых внутренних документов в произвольном порядке, исходя из трактовки требований КВВТ РФ.

\section{Список использованной литературы}

1. Комеков Х. Н. Проблемы реорганизации управления водным транспортом России в период национализации морского и речного флота / Х. Н. Комеков // Исторические, философские, политические и юридические науки, культурология и искусствоведение. Вопросы теории и практики. - 2011. - № 4-3. - С. 58-60.

2. Лянной Г. Г. Становление системы государственного регулирования безопасности предпринимательства в России: ретроспективный анализ / Г. Г. Лянной // Бизнес в законе. -2012 . - № 3. - С. 124-126.

3. Якимова Е. М. Совершенствование системы государственного контроля в Российской Федерации / Е. М. Якимова // Вестник Евразийской Академии административных наук. 2013. - № 1. - С. 51-57.

4. Чучаев А. И. Нарушение правил безопасности движения или эксплуатации водного транспорта (уголовно-правовое и криминологическое исследование) : автореф. дис. ... канд. юрид. наук / А. И. Чучаев. - М., 1982. - 20 с.

5. Костров А. В. Крушение теплохода «Булгария»: проблемы совершенствования законодательства в области предупреждения и ликвидации чрезвычайных ситуаций на водном транспорте / А. В. Костров, В. И. Галочкин, С. А. Титов // Проблемы безопасности и чрезвычайных ситуаций. -2011 . - № 6. - С. 31-50.

6. Диканова Т. А. О законности в сфере безопасности движения и эксплуатации внутреннего водного транспорта / Т. А. Диканова, В. В. Ястребов // Вестник Академии Генеральной прокуратуры Российской Федерации. - 2011. - № 4 (24). - С. 42-48.

7. Сазонов А. А. Актуальные вопросы повышения безопасности судоходства / А. А. Сазонов, В. С. Добровольский // Вестник Волжской государственной академии водного транспорта. -2011 . - № 29 . - С. $86-90$.

8. Совершенствование законодательства в сфере защиты прав и свобод человека и гражданина: обзор предложений по изменению законодательства / Е. М. Якимова, В. В. Чуксина, Л. С. Гетьман, И. Г. Смирнова // Совершенствование законодательства в сфере защиты прав человека и гражданина: проблемы и перспективы / отв. ред. Е. М. Якимова. - Иркутск : Изд-во БГУЭП, 2013. - Ч. 1. - С. 2-30.

9. Якимова Е. М. Административно-правовые способы обеспечения безопасности предпринимательской деятельности / Е. М. Якимова // Вестник Новосибирского государственного университета. Сер.: Право. - 2014. - Т. 10, вып. 1. - С. 24-30.

10. Аверічев I. М. Транспортна безпека як особливий вид економічної безпеки / I. М. Аверічев // Водный транспорт. - 2013. — № 2 (17). - С. 53-57.

11. Лянной Г. Г. Механизм административно-правового регулирования обеспечения безопасности предпринимательской деятельности / Г. Г. Лянной // Научное обозрение. Сер. 2, Гуманитарные науки. - 2012. - № 3-4. - С. 109-113.

\section{Baikal Research Journal}

электронный научный журнал Байкальского государственного университета 
12. Кошутин М. А. Модернизация управления водным транспортом в Вологодском регионе / М. А. Кошутин // Вестник Череповецкого государственного университета. - 2011. T. 2, № 2-30. - C. 19-22.

\section{References}

1. Komekov Kh. N. Problems of restructuring Russia's water transport management during the period of sea and river fleets nationalization. Istoricheskie, filosofskie, politicheskie $i$ yuridicheskie nauki, kul'turologiya i iskusstvovedenie. Voprosy teorii i praktiki = Historical, philosophical, political and legal science, culturology and art criticism. Issues of theory and practice, 2011, no. 4-3, pp. 58-60. (In Russian).

2. Lyannoi G. G. Establishing. Biznes $v$ zakone =Business in law, 2012, no. 3, pp. 124-126. (In Russian).

3. Yakimova E. M. Improvement of Governmental Control System in the Russian Federation. Vestnik Evraziiskoi Akademii administrativnykh nauk= Herald of Eurasian Academy of Administrative Sciences, 2013, no. 1, pp. 51-57. (In Russian).

4. Chuchayev A. I. Narushenie pravil bezopasnosti dvizheniya ili ekspluatatsii vodnogo transporta (ugolovno-pravovoe i kriminologicheskoe issledovanie). Avtoref. Kand. Diss. [Violation of rules of traffic safety and transport operations (criminal-civil and criminological investigation]. Cand. Diss. Thesis]. Moscow, 1982. 20 p.

5. Kostrov A. V., Galochkin V. I., Titov S. A. The collapse of the ship «Bulgars»: problems of improving legislation in the area of prevention and liquidation of emergency situations in water transport. Problemy bezopasnosti i chrezvychainykh situatsii = Problems of Safety and Emergency Situations, 2011, no. 6, pp. 31-50. (In Russian).

6. Dikanova T. A., Yastrebov V. V. On the Issue of Legality in the Sphere of Traffic and Maintenance Safety of the Domestic Water Transport. Vestnik Akademii General'noi prokuratury Rossiiskoi Federatsii = Bulletin of the Academy of the R. F. Prosecutor General's Office, 2011, № 4 (24), pp. 42-48. (In Russian).

7. Sazonov A. A., Dobrovolsky V. S. Topical issues of increasing safety of waterborne traffic. Vestnik Volzhskoi gosudarstvennoi akademii vodnogo transporta = Bulletin of Volga State University of Water Transport, 2011, no. 29, pp. 86-90. (In Russian).

8. Yakimova E. M., Chuksina V. V., Get'man L. S., Smirnova I. G. Mastering legislation in the sphere of protection and freedom of human and civil rights: review of proposals on changing legislation. In Yakimova E. M. (ed.). Sovershenstvovanie zakonodatel'stva $v$ sfere zashchity prav che-loveka i grazhdanina: problemy $i$ perspektivy [Mastering legislation in the sphere of protection of human and civil rights: problems and prospects]. Irkutsk, Baikal State University of Economics and Law Publ., 2013, pr. 1. pp. 2-30. (In Russian).

9. Yakimova E. M. Legal and administrative methods of supporting business in the Russian Federation. Vestnik Novosibirskogo gosudarstvennogo universiteta. Seriya: Pravo = Bulletin of Novosibirsk State University. History and Philology, 2014, vol. 10, iss. 1, pp. 25-30. (In Russian).

10. Averichev I. M. Transport safety as a special type of economic safety. Vodnyi transport = Water Transport, no. 2 (17), pp. 53-57. (In Ukrainian).

11. Lyannoi G. G. Mechanism of administrative and legal regulation of safety insurance of enterprising activity. Nauchnoe obozrenie. Seriya 2, Gumanitarnye nauki = Science Review: Humanities Research, 2012, no. 3-4, pp. 109-113. (In Russian).

12. Koshutin M. A. Modernization of water transport management in Vologda Region. Vestnik Cherepovetskogo gosudarstvennogo universiteta $=$ Bulletin of Cherepovetsk State University, 2011, no. 2-30, vol. 2, pp. 19-22. (In Russian).

\section{Информация об авторах}

Устинов Андрей Николаевич - магистрант, кафедра конституционного и административного права, Юридический институт, Байкальский государственный университет, 664003, г. Иркутск, ул. Ленина, 11; главный консультант, аппарат Уполномоченного по правам человека в Иркутской области, 664027, г. Иркутск, ул. Горького, 31, e-mail: marketgarden@rambler.ru.

Таскаев Николай Николаевич - кандидат юридических наук, доцент, кафедра конституционного и административного права, Юридический институт, Байкальский государственный университет, 664003, г. Иркутск, ул. Ленина, 11, e-mail: irifom@mail.ru.

\section{Baikal Research Journal}




\section{Authors}

Andrei N. Ustinov - Master Degree Student, Chair of Constitutional and Administrative Law, Juridical Institute, Baikal State University, 11 Lenin St., 664003, Irkutsk, Russian Federation; Chief Consultant, Office of the Commissioner for Human Rights in Irkutsk Oblast, 51 Gorky St., 664003, Irkutsk, Russian Federation; e-mail: marketgarden@rambler.ru.

Nikolai N. Taskyaev - PhD in Law, Associate Professor, Chair of Constitutional and Administrative Law, Juridical Institute, Baikal State University, 11 Lenin St., 664003, Irkutsk, Russian Federation; e-mail: irifom@mail.ru.

\section{Библиографическое описание статьи}

Устинов А. Н. Проблемы административно-правового регулирования функционирования водного транспорта в России / А. Н. Устинов, Н. Н. Таскаев // Baikal Research Journal. 2016. 一 T. 7, № 5. — DOI : $10.17150 / 2411-6262.2016 .7(5) .18$.

\section{Reference to article}

Ustinov A. N., Taskayev N. N. Problems of administrative and legal regulation of functioning of water transport in Russia. Baikal Research Journal, 2016, vol. 7, no. 5. DOI : 10.17150/24116262.2016.7(5).18. (In Russian).

\section{Baikal Research Journal}

